\title{
Comparative analysis of university matriculation examination and post university matriculation examination admission models in Lagos State University
}

\author{
Benjamin Segun Aribisala ${ }^{1,2}$, Olanrewaju Abayomi Dosunmu $u^{3,4}$, Moses Adebowale Akanbi $^{3^{*}}$ and Ismail \\ Olanrewaju Shittu ${ }^{4}$ \\ ${ }^{1}$ Department of Computer Sciences, Lagos State University, Lagos \\ ${ }^{2}$ Brain Research Imaging Centre, Division of Neuroimaging Sciences, University of Edinburgh, UK \\ ${ }^{3}$ Department of Mathematics, Lagos State University, Lagos; \\ ${ }^{4}$ Department of Statistics, University of Ibadan, Ibadan
}

\begin{abstract}
There have been issues about the predictive power of the University Matriculation Examination (UME) and most Nigerian universities now conduct an additional screening examination called the post-UME. Some have reported that post-UME is a better predictor of students' performances than the UME while others have the contrary. Hence, it is still not clear whether post-UME is better than UME. To examine this issue further, the researchers modelled association between entrance exam and academic performance measured by Cumulative Grade Point Average (CGPA) of 381 students who were admitted to eight undergraduate programmes at Lagos State University. Regression analysis showed that UME ( standardized $\beta$ : first year $=-0.06, p=0.214$; final year $=-0.06, p=$ 0.217 ) and General Certificate Ordinary Level, $\mathrm{O} / \mathrm{L}(\beta$ : first year $=0.03, p=0.591$; final year $=0.02, p=0.727)$ were not significantly related to CGPA. However post-UME was significantly associated with CGPA ( $\beta$ : first year $=0.36, \mathrm{p}<0.001$; final year $=0.37, \mathrm{p}<0.001$ ). Post-UME explained $12.75 \%$ and $13.58 \%$ variations in the first and final year CGPA respectively. The model that included both post-UME and O/L in the same model showed that they jointly explained $13.07 \%$ and $13.81 \%$ variations in the first and final year performances respectively Similar results were obtained when UME was added to the model. It was found that post-UME is a better predictor of students' performances than UME, and the combined $\mathrm{O} / \mathrm{L}$ and post-UME is no different from the combined $\mathrm{O} / \mathrm{L}, \mathrm{UME}$ and post-UME or post-UME only. The results suggest that admission criteria should be based largely on post-UME.
\end{abstract}

Keywords: UME, O/L, Post-UME, University Entrance Examination, University Performance

DOI: http://dx.doi.org/10.4314/ejst.v11i2.4

\section{INTRODUCTION}

University is a place of learning and a form of industry, so to say, which produces the main manpower of a nation. Many scientific breakthroughs and technological advancements are products of researches conducted within the university. Nigerian universities have also been instrumental in the training of professionals and leaders, and it is almost a requirement that only university graduates are allowed to hold some positions of responsibility in Nigeria (Odia and Odia, 2017).

Currently in Nigeria, only very small percentage of those wanting to move from secondary

\footnotetext{
*Corresponding author: Moses.Akanbi@lasu.edu.ng

(C) This is an Open Access article distributed under the terms of the Creative Commons Attribution License (http://creativecommons.org/licenses/CC BY4.0).
} 
school to university is offered admission due to limited admission spaces (Odia and Odia, 2017). Additionally, the rate of drop-outs in Nigerian universities is high, which could be blamed on poor academic performance of the students, though there could be such other contributing factors as poor health and financial constraint. Also, there are allegations that the quality of Nigerian graduates has been questioned both within and outside the country. Although there could be many causes of poor quality, some have blamed the admission process (Igwe and Adiku, 2012). It is hence very important that the university admission is not only fair but also robust enough to select only those who are qualified (van Ooijen-van der Linden et al., 2017) and capable of becoming the professionals needed by the country and the world at large.

The most common path to university education in Nigeria is Primary - Secondary - University. At the end of primary school education, all students are expected to sit for the national common entrance examination before they are offered admission into the secondary school. Similarly, at the end of secondary school education, students are required to sit for the Ordinary Level $(\mathrm{O} / \mathrm{L})$ examinations such as the West African Senior School Certificate Examination (WASSCE hereafter), conducted by the West African Examinations Council (WAEC) or Senior School Certificate Examination (SSCE hereafter), conducted by the National Examinations Council (NECO). The WASSCE and SSCE are similar to the General Certificate of Education (GCE) $\mathrm{O} / \mathrm{L}$ conducted in many countries.

In Nigeria before 1978, the criteria for admission from secondary school to university varied from one university to the other, which caused admission to be determined by each university (Asein and Lawal, 2007). That decentralized system led to lack of standard and uniformity, multiple admissions and deprivation of admission for qualified candidates. The Joint Admissions and Matriculation Board (JAMB) was established by the Federal government of Nigeria in 1978 to conduct the University Matriculation Examinations (UME), thereby to unify and standardize university admission process in Nigeria (Salim, 2006'; Asein and Lawal, 2007). UME has recently been rebranded as Universal Tertiary Matriculation Examinations (UTME) to allow JAMB to also manage the entrance examinations into colleges and polytechnics. We use UME to represent UME or UTME throughout this paper. All students seeking admission into a Nigerian university are required to pass, at credit level, at least five $\mathrm{O} / \mathrm{L}$ subjects relevant to the intended undergraduate programme, including English Language. They are also required to sit for the UME and meet the cut-off mark for that particular programme determinable by each university. UME takes place once a year at the same time and on the same day throughout Nigeria at government approved locations. The main requirement for attempting the UME is to have attempted $\mathrm{O} / \mathrm{L}$ examination. In view of this, students can sit for the UME immediately after $\mathrm{O} / \mathrm{L}$ examination, although some students attend one-year special coaching classes before attempting the UME. Most of the special coaching centres are not government owned, nor are they standardized or regulated by the government. The UME questions are the same for all candidates who are required to attempt the Use of English (100 questions) and any other three subjects (50 questions each) relevant to the intended undergraduate programme. Candidates are allowed maximum of four hours to attempt all the questions. The curriculum for UME is available to all candidates and comprises of the $\mathrm{O} / \mathrm{L}$ curriculum with some elements of GCE Advanced Level 
(A/L). The difficulty level of UME is, hence, a bit higher than that of $\mathrm{O} / \mathrm{L}$.

However, many Nigerian universities have recently doubted the trustworthiness of the UME, which has led to the introduction of an institution specific screening test called the post-UME. The postUME is conducted as an oral interview by some institutions while others use written tests. And still some others combine oral and written tests. Post-UME, whose level of difficulty varies among institutions, is not the same across institutions In many universities which use a written type of the post-UME, the examinations are conducted as an aptitude test, which consists of English, Mathematics and three or more subjects relevant to the student's proposed study. In Lagos State University (LASU), for example, the post-UME comprises of 100 equally weighted multiple choice questions of the same standard and difficulty level as the UME, selected from English and other three or four subjects related to the candidate's choice of course. Equal number of questions is selected from each subject to make the 100 questions, i.e. for a student doing four subjects, 25 questions are selected from each subject. The examination is conducted inside LASU, and candidates are given 90 minutes to attempt all the 100 questions.

The credibility and validity of the UME has recently been attracting lots of criticism. The main concern has been that UME is not a good predictor of university undergraduate academic performance. This view is supported by some studies which found no association between UME and undergraduate performance (Afolabi et al., 2007, Adeniyi et al., 2010) but found association between post-UME and performance (Ajaja, 2010, Osakuade, 2011). However, some studies have reported that UME is a good predictor of performance (Afolabi et al., 2007a; Ajaja, 2010; Osakuade, 2011; Igwe and Adiku, 2012). Others have argued that admission requirement should be based on the combination of UME and General Certificate of Education (GCE) Ordinary Level $(\mathrm{O} / \mathrm{L})$ because they found that such combination is a better predictor of undergraduate academic performance than UME only (Oyebola, 2006, Obioma and Salau, 2007, Afolabi et al., 2007, Adeniyi et al., 2010).

Most of the existing studies have limitations in that they either investigated students' performances in only one academic session (Oyebola, 2006, Afolabi et al., 2007, 2007a; Igwe and Adiku, 2012) or focused on one degree programme/ department (Omigbodun and Omigbodun, 2003; Bamidele and Odusola, 2006, Yates and James, 2006; Afolabi et al., 2007, 2007a; Adeniyi et al., 2010). Additionally, most of the studies did not adjust for gender in their analyses although gender has been considered to be a predictor of undergraduate academic performance (Omigbodun and Omigbodun, 2003, Bamidele and Odusola, 2006). Hence, it is still not clear whether UME is a good predictor of academic performance at undergraduate level, or whether post-UME is better than UME at predicting student's performance.

The current study investigated the academic performances of undergraduate students using their first and final year's Cumulative Grade Point Average (CGPA). Its aim was to determine whether UME could predict academic performance or not, and also to determine which of UME or post-UME is a better predictor of student's performance. The researchers modelled associations using regression analysis and gender was included as a covariate to see if it has any influence on the association between university entrance examinations and academic performance. 
The following were the research questions

1. Does gender influence university entrance exam?

2. Does gender influence academic performance in university?

3. Does each of the Uuniversity entrance exam (O/L, UME, Post-UME) predict academic performance in the niversity (first year CGPA, final year CGPA)? If so which of the University entrance exams are the best predictor of academic performance in the Uuniversity?

4. Do combined university entrance exams (all the three or any two of O/L, UME or Post-UME) have more predictive power at predicting academic performance in the University than one single entrance exam?

5. Does gender have any influence on the association between university entrance exams and academic performance in university?

The identification of university entrance exam that gives significant predictors of university students' academic performance could offer the following benefits to Lagos State University. Briefly, the study is significant because it helps the government to formulate a robust admission policy and identify the best candidates for any University programme

\section{MATERIALS AND METHODS}

\section{The Study Population}

The study investigated documents of 971 LASU undergraduate students who were given admission in the 2007/2008 academic session under eight programmes: Accounting, Banking and Finance, Business Administration, Industrial Relations \& Personnel Management, Insurance, Marketing, Physical \& Health Education and Public Administration. The UME scores, aggregate scores, Cumulative Grade Point Average (CGPA) at first and final year and gender information were used for statistical analysis. There was no direct contact with human participants, and there is no institutional board or equivalent board that gives approval of data driven study in our institution. In view of this, there was no ethical approval for the study. Additionally, we did not obtain informed consent from participants because the study was conducted on the data available.

\section{Computation of Aggregate Score for Admission into LASU}

All students seeking admission into LASU for an undergraduate degree programme are required to sit for a post-UME screening test organised by LASU. As it is common with other universities in Nigeria, LASU advertises its post-UME tests on two or three national newspapers as well as on the university's website and weekly official bulletin. The candidates then apply online through the university's website and thereafter report at the university on announced dates for the tests. The admission and selection requirements are based on three main criteria (Lagos State University Nigeria, 
2013): (1) Five O/L credit passes at not more than two sittings to include English Language and Mathematics; (2) A minimum score of 200 out of 400 in the UME, for which subjects must include English Language and three other subjects relevant to the degree programme; and (3) A minimum of $50 \%$ aggregate score computed. Aggregate score is combination of $\mathrm{UME}, \mathrm{O} / \mathrm{L}$ and post-UME, each contributing $25 \%, 25 \%$ and $50 \%$, respectively (Equation 1, (LASU, 2013)). It is worth noting that UME, $\mathrm{O} / \mathrm{L}$ and post-UME attract maximum scores of 400,50 and 100 , respectively. Thus, UME is multiplied by 0.0625 (or divided by 16) to convert it to $25 \%, \mathrm{O} / \mathrm{L}$ by 0.5 to convert to $25 \%$ and postUME test by 0.5 to convert to $50 \%$. Equation 1 is unique to LASU and each Nigerian university uses different formulae.

Aggregate $=0.0625^{*} \mathrm{UME}$ score $+0.5^{*} \mathrm{O} / \mathrm{L}$ score + $0.5 *$ post-UME score

Note that the maximum scores for the UME and post-UME are the actual maximum scores obtainable from the examinations (400 and 100, respectively), whereas the $\mathrm{O} / \mathrm{L}$ score is computed from the candidate's five best subjects relevant to the proposed programme of study using equation 2 . Equation 2 is equally unique to LASU, and other universities use different equations.

$\mathrm{O} / \mathrm{L}$ score $=$ Total $\mathrm{O} / \mathrm{L}$ Point + Sitting Point ........................................2

where the Total $\mathrm{O} / \mathrm{L}$ Point is computed by converting the students grade in each subject to points using $\mathrm{C} 6=3, \mathrm{C} 5=4, \mathrm{C} 4=5, \mathrm{~B} 3$ (A3) $=6, \mathrm{~B} 2(\mathrm{~A} 2)=7, \mathrm{~A} 1=8$ and the Sitting Point is awarded based on the number of times the candidate sat the $\mathrm{O} / \mathrm{L}$ examination to pass the five relevant subjects; the maximum allowed number of sitting is 2 . One sitting attracts 10 points and 2 sittings attract 5 points. Note that in Nigeria, the $\mathrm{O} / \mathrm{L}$ grading system uses the scale $50 \%-54 \%$ $=\mathrm{C} 6,55 \%-59 \%=\mathrm{C} 5,60 \%-64 \%=\mathrm{C} 4,65 \%-$ $69 \%=\mathrm{A} 3,70 \%-74 \%=\mathrm{A} 2$ and $75 \%-100 \%=\mathrm{A} 1$

\section{Computation of Cumulative Grade Point Average (CGPA) and Performance Measure}

All Nigerian universities use the CGPA as a measure of academic performance for undergraduate programmes. The CGPA is the upto-date average of the Grade Points (GP) earned by the student in all the courses taken during his/ her programme of study. Generally, each course is weighted by a quantity called the Number of Units (NU), which is the number of weekly contact hours that the lecturer had with the students, in the form of lectures, tutorials or practical classes. Three hours of practical or tutorial classes count as 1 unit while 1 hour of lecture counts as 1 unit. The CGPA is an indication of the student's overall performance at any point in the training/ educational programme. To compute the CGPA, the Credit Point (derived from the student's grade) of each course in all semesters are multiplied by the NU. The results obtained are then summed and divided by the total number of units offered in all semesters. The grading system uses $0-39 \%=0$, $40 \%-44 \%=1,45 \%-49 \%=2,50 \%-59 \%=3$, $60 \%-69 \%=4,70 \%-100 \%=5$.

Some previous studies measured university academic performance using the first year CGPA (Adeyemo and Gbemisola, 2006, Afolabi et al., 2007, 2007a, Adeniyi et al., 2010) while others used the final year CGPA (Bamidele and Odusola, 2006; Obioma and Salau, 2007). As noted before, the researchers in the current study used both the 
first and final year CGPA as measures of university academic performance. This was because the firstyear performance could enable us to determine the students' ability in their programmes at the point of entry, which could in turn provide diagnostic information on how to mentor them. The researchers also included the final year performance because it could give us the overall performance of the students. Including both the first and the final year CGPAs also helped us to see if there were any difference in the associations between the entrance exams and the two measures of University academic performances.

\section{Statistical Analysis}

Both the descriptive and inferential statistics were used in this study. The descriptive statistics used were mean and standard deviation scores, which were computed for male and female students, for each entrance examination (UME, Post-UME, $\mathrm{O} / \mathrm{L}$ and aggregate) and for each measure of performance (first year and fourth year CGPA's). Inferential Statistics used independent t-test and multiple regression models. Two-sample t-test was used to determine whether or not gender had any significant influence on both the entrance examinations scores and university performance scores. Multiple regression models, on the other hand, were used to determine relationships between the entrance examination scores and university performance scores.

All statistical analyses were performed using IBM SPSS version 19.0 (SPSS Inc., an IBM Company, Chicago III, USA), with all statistical tests being two-tailed, and $\mathrm{p}$ values $<0.05$ being considered statistically significant. The graphical assessment of the distributions of the performance scores using histograms and Quantile-Quantile plots revealed that they are almost normally distributed. The comparison of non-parametric (using Mann Whitney-U test) and parametric (using t-test) tests gave similar results (data not presented for brevity but available on request). In view of these, the male and female's performance scores were compared using independent t-tests, and $p$ values were corrected for multiple comparisons using Bonferroni correction. Associations between entrance examinations and university performances were examined using multivariate linear regression models. In these models, each university performance parameter (CGPA first year and CGPA final year) was the dependent variable and each entrance examination result $(\mathrm{O} / \mathrm{L}$, UME, PostUME and aggregate) was the independent variable. Separate models which predicted performances from the combined entrance examinations were used to assess how much variance in performance is accounted for by the combined entrance examination results. The models combined $\mathrm{O} / \mathrm{L}$ and UME; O/L and post-UME; UME and post-UME; and finally $\mathrm{O} / \mathrm{L}, \mathrm{UME}$ and post-UME. Gender was introduced as a covariate in a stepwise approach to allow identification of gender effect on the associations between entrance examinations and performances. We used the false-discovery rate correction to correct for multiple testing.

\section{RESULTS}

Amongst the 971 students offered admission to the eight programmes investigated, approximately $79(8 \%)$ discontinued at the end of year one for reasons such as poor academic performance, poor health condition and financial constraint. 
Another $85(9 \%)$ withdrew between years 2 and 4 because of poor academic performance or financial constraints. Of the remaining 807 (83\%), 426 $(53 \%)$ did not graduate at the time of the study because they had not passed the minimum number of units required for graduation, reducing the final sample size to 381 , i.e. $39 \%$ (214 male, $56 \%$, Table 1) of the total intake. Hence, the final sample size for this study consists of 381 students across the eight programmes, for which there was complete data, suitable for this study.

Male students were found to perform better than female students in post-UME (mean $\pm \mathrm{SD}$, male $=48.12 \pm 10.51$, female $=43.63 \pm 10.62$, $\mathrm{p}<0.001$ ), aggregate (male $=57.49 \pm 5.55$, female $=34.93 \pm 4.57, \mathrm{p}<0.001)$ and first year university examination $($ male $=3.05 \pm 0.63,2.82 \pm 0.60$, $\mathrm{p}<0.0001$ ), but there were no gender related differences in $\mathrm{O} / \mathrm{L}, \mathrm{UME}$ and final year university examination.

Table 1: Descriptive statistics for entrance examinations and measures of performance. $N=381$ (Male $=214$, Female $=167)$.

\begin{tabular}{lll}
\hline & Gender & Mean (SD) \\
\hline UME, maximum of 400 & Male & $250(22.06)$ \\
Post-UME, maximum of 50 & Female & $247.43(23.12)$ \\
& Male & $48.12(10.51)^{+}$ \\
O/L (\%), maximum of 50 & Female & $43.60(10.62)$ \\
& Male & $34.63(4.78)$ \\
Aggregate (\%) & Female & $34.93(4.57)$ \\
First year performance, maximum of 5 & Male & $57.49(5.55)^{+}$ \\
& Female & $55.20(5.68)$ \\
Final year performance, maximum of 5 & Male & $3.05(0.63)^{+}$ \\
& Female & $2.82(0.60)$ \\
\hline
\end{tabular}

+ Male significantly greater than female $(\mathrm{p}<0.05)$ after correcting for multiple comparisons using Bonferroni. UME $=$ University Matriculation Examination.

In the regression models and before the inclusion of gender, there was no significant relationship between performance at the first year in the university and $\mathrm{O} / \mathrm{L}$ (standardized $\beta=0.03, \mathrm{p}=$ 0.59 , Table 2 , Figure 1$)$ or $\operatorname{UME}(\beta=-0.06, \mathrm{p}=$
0.21). However, higher scores of post-UME were significantly associated with better performance at the first-year university examination $(\beta=0.36, \mathrm{p}$ $<0.01$ ). 
Table 2: Correlation between measures of first year performance in the university and entrance examinations results

\begin{tabular}{|c|c|c|c|c|c|c|c|}
\hline & & & Gender & cluded & $\begin{array}{l}\mathrm{Ge} \\
\text { inc }\end{array}$ & $\begin{array}{l}\text { der } \\
\text { uded }\end{array}$ & \\
\hline Model & & beta & $\mathrm{P}$ & $\begin{array}{l}\text { Rsquare } \\
(\%)\end{array}$ & Beta & $\mathrm{p}$ & Rsquare(\%) \\
\hline 1 & Aggregate & 0.33 & $<0.01$ & 10.93 & 0.31 & $<0.01$ & 12.38 \\
\hline & Gender & & & & -0.12 & 0.01 & \\
\hline 2 & UME & -0.06 & 0.21 & 0.41 & -0.07 & 0.14 & 3.93 \\
\hline & Gender & & & & -0.19 & $<0.01$ & \\
\hline 3 & Post-UME & 0.36 & $<0.01$ & 12.75 & 0.33 & $<0.01$ & 14.00 \\
\hline & Gender & & & & -0.11 & 0.02 & \\
\hline 4 & $\mathrm{GCE} \mathrm{O} / \mathrm{L}$ & 0.03 & 0.59 & 0.08 & 0.03 & 0.51 & 3.49 \\
\hline & Gender & & & & -0.19 & $<0.01$ & \\
\hline 5 & UME & -0.06 & 0.22 & 00.48 & -0.07 & 0.14 & 4.03 \\
\hline & $\mathrm{GCE} \mathrm{O} / \mathrm{L}$ & 0.03 & 0.60 & & 0.03 & 0.51 & \\
\hline & Gender & & & & -0.19 & $<0.01$ & \\
\hline 6 & Post-UME & 0.36 & $<0.01$ & 13.07 & 0.34 & $<0.01$ & 14.34 \\
\hline & $\mathrm{GCE} \mathrm{O} / \mathrm{L}$ & 0.06 & & & 0.06 & 0.22 & \\
\hline & Gender & & & & -0.12 & 0.02 & \\
\hline 7 & UME & -0.02 & 0.70 & 12.78 & -0.03 & 0.55 & 14.08 \\
\hline & Post-UME & 0.36 & $<0.01$ & & 0.33 & $<0.01$ & \\
\hline & Gender & & & & -0.12 & 0.02 & \\
\hline 8 & UME & -0.02 & 0.71 & 13.10 & -0.03 & 0.57 & 14.41 \\
\hline & Post-UME & 0.36 & $<0.01$ & & 0.33 & $<0.01$ & \\
\hline & $\mathrm{GCE} \mathrm{O} / \mathrm{L}$ & 0.06 & 0.24 & & 0.06 & 0.22 & \\
\hline & Gender & & & & -0.12 & $0.02^{+}$ & \\
\hline
\end{tabular}

Note. Dependent variable was the first-year performance and independent variables were entrance examination results. Values are standardized beta values (and $\mathrm{p}$ values), and r square. Significant values are in boldface.

+ Not significant after correction for multiple testing using the false-discovery rate method.

$\mathrm{UME}=$ University Matriculation Entrance

Models 1 to 4 : performance $=\beta 1 *$ examination $+\beta 2 *$ Gender

Models 5 to 7 : performance $=\beta 1 *$ examination $1+\beta 2 *$ examination $2+\beta 3 *$ Gender

Models 8: performance $=\beta 1 *$ examination $1+\beta 2 *$ examination $2+\beta 3 *$ examination $3+\beta 4 *$ Gender 


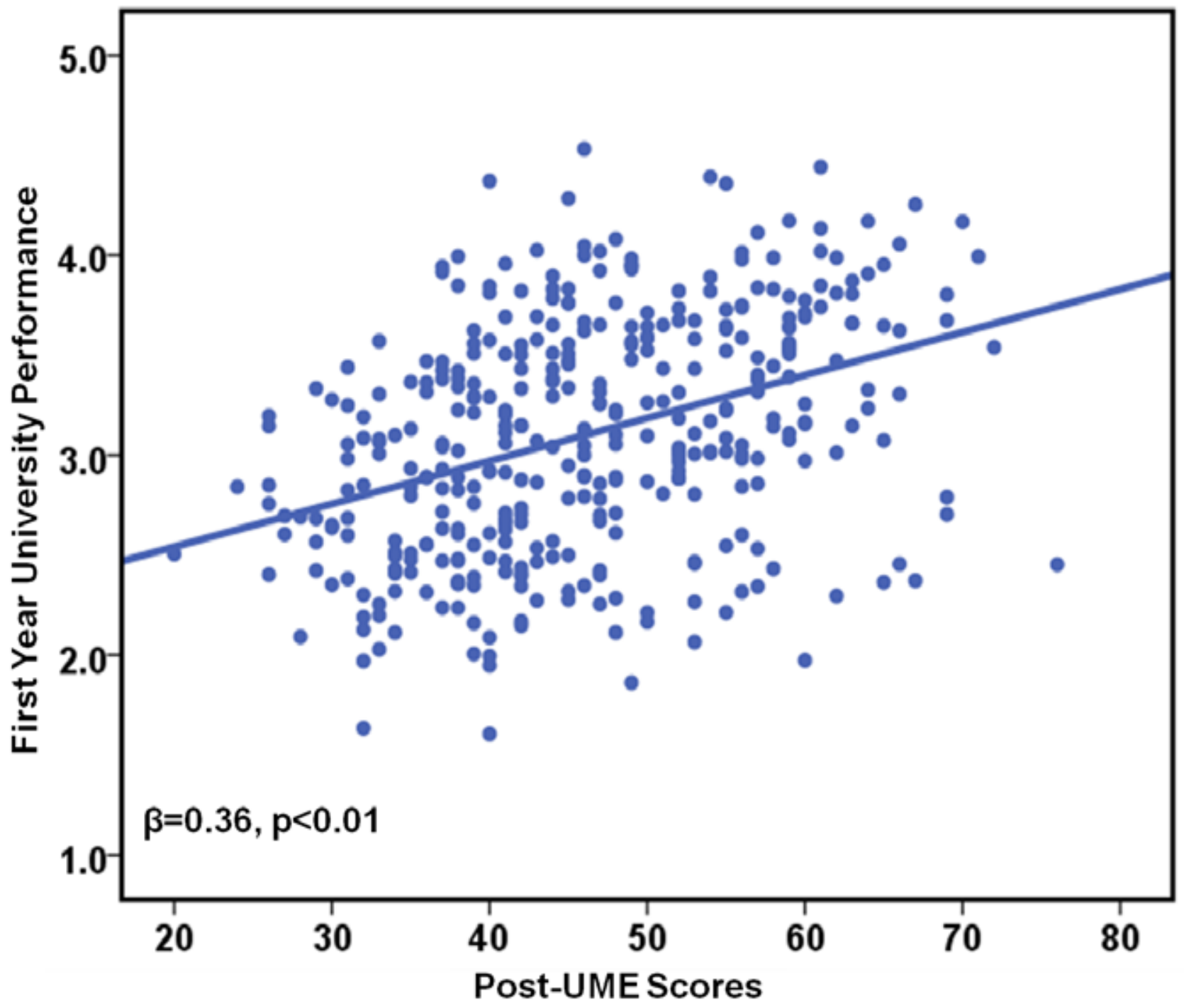

Figure 1: Scatter plots with regression lines and standardized beta values (and p) of university first year performance measure against post-UME (crosses). Standardized beta and P values were calculated after allowing the model to adjust for gender.

Additionally, higher scores of aggregates were significantly associated with better performance at the first-year university examination $(\beta=0.33$, $\mathrm{p}<0.01)$. Inclusion of gender did not attenuate associations, and similar results were obtained when final year performance was predicted from entrance examinations (Table 3 ).
Post-UME explained $12.75 \%$ and $13.58 \%$ variations in the first and final year performances respectively (Table 2, Table 3 ). The model that included both $\mathrm{O} / \mathrm{L}$ and post-UME in the same model showed that they jointly explained $13.07 \%$ and $13.81 \%$ variations in the first and final year performances, respectively. O/L, UME and post- 
Table 3: Correlation between measures of final year performance in the university and entrance examinations results

\begin{tabular}{|c|c|c|c|c|c|c|c|}
\hline \multirow[b]{2}{*}{ Model } & & \multirow[b]{2}{*}{ Beta } & \multicolumn{2}{|c|}{ Gender not included } & \multicolumn{3}{|c|}{ Gender included } \\
\hline & & & $\mathrm{P}$ & Rsquare (\%) & beta & $\mathrm{p}$ & Rsquare(\%) \\
\hline \multirow[t]{2}{*}{1} & Aggregate & 0.34 & $<0.01$ & 11.58 & $\mathbf{0 . 3 3}$ & $<0.01$ & 11.90 \\
\hline & Gender & & & & -0.06 & 0.25 & \\
\hline \multirow[t]{2}{*}{2} & UME & -0.06 & 0.22 & 0.40 & -0.07 & 0.17 & 2.00 \\
\hline & Gender & & & & -0.13 & 0.01 & \\
\hline \multirow[t]{2}{*}{3} & Post-UME & 0.37 & $<0.01$ & 13.58 & 0.36 & $<0.01$ & 13.80 \\
\hline & Gender & & & & -0.05 & 0.33 & \\
\hline \multirow[t]{2}{*}{4} & $\mathrm{O} / \mathrm{L}$ & 0.02 & 0.73 & 0.03 & 0.02 & 0.67 & 1.55 \\
\hline & Gender & & & & -0.12 & $\mathbf{0 . 0 2}^{+}$ & \\
\hline \multirow[t]{3}{*}{5} & UME & -0.06 & 0.22 & 00.43 & -0.07 & 0.16 & 02.05 \\
\hline & $\mathrm{O} / \mathrm{L}$ & 0.02 & 0.74 & & 0.02 & 0.68 & \\
\hline & Gender & & & & -0.13 & 0.01 & \\
\hline \multirow[t]{3}{*}{6} & Post-UME & 0.37 & $<0.01$ & 13.81 & 0.36 & $<0.01$ & 14.04 \\
\hline & $\mathrm{O} / \mathrm{L}$ & 0.05 & 0.31 & & 0.05 & 0.31 & \\
\hline & Gender & & & & -0.05 & 0.32 & \\
\hline \multirow[t]{3}{*}{7} & UME & -0.02 & 0.72 & 13.61 & -0.02 & 0.66 & 13.85 \\
\hline & Post-UME & 0.37 & $<0.01$ & & 0.36 & $<0.01$ & \\
\hline & Gender & & & & -0.05 & 0.31 & \\
\hline \multirow[t]{4}{*}{8} & UME & -0.02 & 0.74 & 13.84 & -0.02 & 0.67 & 14.08 \\
\hline & Post-UME & 0.37 & $<0.01$ & & 0.36 & $<0.01$ & \\
\hline & $\mathrm{O} / \mathrm{L}$ & 0.05 & 0.32 & & 0.05 & 0.31 & \\
\hline & Gender & & & & -0.05 & 0.30 & \\
\hline
\end{tabular}

Note. Dependent variable was the final year performance and independent variables were entrance examination results. Values are standardized beta values (and $\mathrm{p}$ values), and $\mathrm{r}$ square. Significant values are in boldface.

+ Not significant after correction for multiple testing using the false-discovery rate method

$\mathrm{UME}=$ University Matriculation Entrance

Models 1 to 4 : performance $=\beta 1 *$ examination $+\beta 2 *$ Gender

Models 5 to 7 : performance $=\beta 1 *$ examination $1+\beta 2 *$ examination $2+\beta 3 *$ Gender

Models 8: performance $=\beta 1 *$ examination $1+\beta 2 *$ examination $2+\beta 3 *$ examination $3++\beta 4 *$ Gender

UME jointly explained $13.10 \%$ and $13.84 \%$ variations in the first and final year performances. The models that included multiple predictors showed that the total percentage of variation in the final year performance was slightly lower than those of the first-year performance (Table 3). 


\section{DISCUSSION}

In our sample of undergraduate students across many degree programmes, the researchers found that: the Nigerian University Matriculation Examination results and the GCE Ordinary Level School leaving results were not significantly related to undergraduate performance, neither in the first nor in the final year. However, post-UME was significantly associated with performance in the first and final year. These suggest that post-UME is a better predictor of students' performances than $\mathrm{UME}$ or $\mathrm{O} / \mathrm{L}$. We also found that the combined $\mathrm{O} / \mathrm{L}$ and post-UME did not have higher predictive value than post-UME only. The predictive potential of the combined $\mathrm{O} / \mathrm{L}$ and post-UME was the same with that of the combined O/L, UME and postUME. These suggest that the combination of $\mathrm{O} / \mathrm{L}$ or UME with the post-UME did not increase the predictive potential of post-UME, hence the post$\mathrm{UME}$ is the only variable that has predictive value out of all the predictor variables investigated. We also found that male students performed better than female students in post-UME, aggregate and first year university examination, but there were no gender related differences in $\mathrm{O} / \mathrm{L}$, UME or final year university examination. To the best of our knowledge, this is the first study to investigate the predictive power of $\mathrm{O} / \mathrm{L}$, UME and postUME across many programmes in more than one academic session, and accounting for gender in the analyses.

Our finding about lack of significant association between UME and undergraduate performance is consistent with similar studies (Afolabi et al., 2007; Adeniyi et al., 2010) conducted in other universities within Nigeria, but contradicts with others (Afolabi et al., 2007a; Ajaja, 2010; Osakuade, 2011; Igwe and Adiku, 2012). This contradiction is probably because these studies investigated students from only one programme (Afolabi et al., 2007a) or one department (Ajaja, 2010; Igwe and Adiku, 2012) and did not correct for gender (Afolabi et al., 2007a; Ajaja, 2010; Osakuade, 2011; Igwe and Adiku, 2012). The findings from the investigation of only one department or programme may not be generalizable for all programmes because one programme or department may not be a true representation of all programmes or departments. Our analysis included many programmes and departments within the university. Additionally, not including gender in the analyses may not produce true association between entrance examinations and undergraduate performance because as found in the current study and other similar studies (Omigbodun and Omigbodun, 2003; Bamidele and Odusola, 2006), gender is a predictor of performance. Our analyses adjusted for gender offers a relatively better and valid association between university entrance examination and undergraduate performance.

In agreement with other groups within (Ajaja, 2010; Osakuade, 2011) and outside (FarrokhiKhajeh-Pasha et al., 2012) Nigeria, we found that the university specific screening (post-UME) examination is a better predictor of performance than the national Uniqsversity Matriculation Examination (UME). Our finding that the combined $\mathrm{O} / \mathrm{L}$ and post-UME does not have higher predictive value than post-UME only contradicts the findings from other groups (Oyebola, 2006; Obioma and Salau, 2007; Afolabi et al., 2007; Adeniyi et al., 2010). This could be explained by the fact that these groups, as noted before, investigated only one programme of study or 
did not correct for gender. In contrast, our study included many programmes and also corrected for gender, and can thus be more generalizable and more likely to produce a better association between university entrance examination and undergraduate performance. However, it is notable that our finding that the predictive value of the combined $\mathrm{O} / \mathrm{L}$ and post-UME is the same with that of the combined $\mathrm{O} / \mathrm{L}, \mathrm{UME}$ and post-UME is novel.

It is observed that the percentage of variance explained by the predictor variables investigated appeared to decline after the first year in that the $r$-square for the final year was consistently lower than those of the first year (Table 3). This could suggest that there is a decrease in the strength of predictive power of the predictor variables investigated over years. This finding is consistent with that of other studies (Geiser and Santelices, 2007; Obioma and Salau, 2007). One interpretation of this is that the students' performances at the final year could be affected by other factors not affecting performance at the first year. This is intuitive because the students ought to have spent about three additional years after first year in the university and must have increased their knowledge-base in the field of studies and acquired new set of skills. These factors could vary among students and programmes and hence could influence academic performance. Although such factors were not investigated in this study, they could be interesting areas of inquiry for studies in the future.

The finding of the study revealed that postUME explained only about $15 \%$ of the variation in academic performance and there are several factors that could account for the remaining 85\% of the variation. Some of these are age, parental educational background, types and location of secondary school attended, gap year(s) between completion of secondary school and entrance into the university (Oladokun et al., 2008). Other factors are previous work experience, the number of times a student attempted GCE $\mathrm{O} / \mathrm{L}$, UME or post-UME, parents' societal class, cognitive ability, the subjects taken at $\mathrm{O} / \mathrm{L}$, and quantitative reasoning (Bakare, 1975; Oladokun et al., 2008; Yates and James, 2010) and potential social cohesion among study groups (Ravi 2009). Investigation of these and other factors that could possibly explain the academic performance of our cohort is beyond the scope of the current study. Also, the data needed to properly account for these factors are not currently available. Our future studies will consider investigating these factors and the particular effect of each of them on the university academic performance.

To the best of our knowledge, only one study (Obioma and Salau, 2007) has attempted to predict university academic performance from entrance examinations using many degree programmes or departments. Unlike the current study, that study did not account for gender in the modelling although gender, as stated earlier has been reported to be a predictor of university performance in Nigeria (Omigbodun and Omigbodun, 2003; Bamidele and Odusola, 2006). Additionally, the study of Obioma and Salau (2007) tested for many hypotheses without correcting for multiple testing hence increased the chance of committing type 1 error. The researchers in the present study, however, accounted for multiple testing using the false-discovery rate approach.

The possible reason for the poor predictive power of UME is not clear, and it is beyond the scope of this study. Future studies should attempt to 
determine the reason why UME, which is the main national entrance examination into Nigerian universities, is not able to predict students' performances in the University.

\section{Strengths and Weaknesses of the Study}

The main strength of this study lies in the investigation of many degree programmes across different departments and the use of large sample. This suggests that our findings are generalizable. Another strength is the detailed statistical analyses which allowed adjustment for gender and also corrected for multiple testing to avoid increasing the chance of type 1 error.

Additionally, previous studies measured university academic performance using either the first year CGPA (Adeyemo and Gbemisola, 2006, Afolabi et al., 2007, 2007a; Adeniyi et al., 2010) or final year CGPA (Bamidele and Odusola, 2006; Obioma and Salau, 2007). However, we used both the first and final year CGPA, which enabled us to see if the association between the entrance exams and academic performances in the University stayed the same in the first or final year. We found that the association was not the same; it rather actually got worse. This suggests that the more the students stay in the University, the less the influence of entrance exams. This is a finding unique to our study.

The main limitation of the study is the fact that it was conducted using data from only one university. Including many universities within the country will make the results more generalizable. We are currently talking to colleagues from other universities to establish collaboration with them so as to include most of the universities within Nigeria. Another weakness is the lack of correction for state of origin or where the students sat for the
O/L or UME. Additionally, secondary schools can be broadly divided into state, federal and private based on ownership. It is generally believed that students' performance at secondary school could be a function of the type of school attended. It will be useful to know the effect of the type of schools on the associations reported in our study. At the current time, we do not have access to these data, but our future study will make efforts to include them. Also, the study is limited by the sample size. The analysis included only $39 \%$ of the total number of intakes within the sessions studied. This was due to the fact that only this per cent had the complete data needed for the analysis. Our goal was to investigate only those students who graduated at the end of four sessions. Our future study will include those who graduated at a later session or who spent more than four sessions for a four-session programme, and that might help us to determine if the association between entrance examinations and university performance is the same for those who completed their programme on time and those who spent extra year(s).

In conclusion, post-UME is a better predictor of students' performances than UME and the combined $\mathrm{O} / \mathrm{L}$ and post-UME is not different from the combined $\mathrm{O} / \mathrm{L}$, UME and post-UME; or postUME only. We recommend that admission criteria should be based largely on post-UME.

\section{ACKNOWLEDGEMENTS}

The researchers thank all the staff members of the LASU Integrated Data Centre (LIDC) and Information and Communication Centre of the Lagos State University for their support during the data collection. 


\section{REFERENCES}

Adeniyi, OS., Araoye, MA., Amali, EO., Eru, EU., Ojabo, CO and Alao, OO. (2010). Effect of using combination of O'level results with JAMB score on Student performance in the first two years of medical school in Benue State University, Makurdi. African Journal of Biomedical Research 13:189 - 195.

Adeyemo, AB and Gbemisola K. (2006). Mining Students' Academic Performance using Decision Tree Algorithms. Journal of Information Technology Impact 6:161-170.

Afolabi, AO., Mabayoje, VO., Togun, VA., Oyadeji, AS and Raji, R. (2007). The Effect of mode of Entry into medical school on Performance in the first two years. Journal of Medical Science 7:1021-1126.

Afolabi, AO., Mabayoje, VO., Togun, VA., Oyadeji, AS and Raji, R. (2007a). Selection Criterion for entry into the medical programme of Nigerian Universities - The Efficacy of combining school certificate results with JAMB scores in selection of candidates into the Ogbomosho medical school. African Journal of Biomedical Research 10:203-209.

Ajaja, OP. (2010). Three Years of Post-UME Screening - Influence on Science Education Students' Achievement in Delta University, Abraka". International Journal of Education Science 2:29-40.

Asein, JE and Lawal, Y. (2007). Admission into Tertiary Institutions in Nigeria. In: 33rd Annual Conference of the International Association for Educational Assessment (IAEA) Baku, Azaerbaijan, 33:1-9.
Bakare, CGM. (1975). Some Psychological Correlates of Academic Success and Failure. African Journal of Educational Research 2(1):11-22.

Bamidele, AF And Odusola O. (2006). A Review of the Enrolment and Performance of male and female students in Education/Economics Programme of Obafemi Awolowo University, Ile-Ife. Nigeria Journal of Social Science 12:143-146.

Farrokhi-Khajeh-Pasha, Y., Nedjat, S., Mohammadi, A., Rad, EM,, Majdzadeh, R., Monajemi, F., Jamali, E and Yazdani, S. (2012). The validity of Iran's national university entrance examination (Konkoor) for predicting medical students' academic performance. BMC Medical Education 12(1)60:1-8

Geiser, S and Santelices, MV. (2007). Validity of high school grades in predicting student success beyond the freshman year: High school record vs. standardized tests as indicators of four-year College outcomes. Research \& Occasional paper series, Center for Studies in Higher Education, University of California, Berkeley 6(7):1-35.

Igwe, DO and Adiku, O. (2012). Measurement of intellectual functioning of Nigerian youth: the predictive validity of JAMB/UME in relation to students' performance in University. Educational Research 3:639-644.

LASU, H. (2013). Lagos State University Handbook for Undergraduate Students. Lagos State University Printing Press.

Obioma, G and Salau, M. (2007). The predictive validity of public examination: A case study of Nigeria. Annual Conference of 
International Association for Educational Assessment (IAEA) held in Baku, Azerbaijan, 16-21.

Odia, JO and Odia, AA. (2017). Accessibility to Higher Education in Nigeria: The Pains, Problems, and Prospects. The Future of Accessibility in International Higher Education, 7:104-124.

Oladokun, VO.,Adebanjo, AT and Charles-Owaba, OE. (2008). Predicting Students' Academic Performance using Artificial Neural Network: A Case Study of an Engineering Course. The Pacific Journal of Science and Technology 9(1):72-79.

Omigbodun, OO and Omigbodun, AO. (2003). Influence of gender on undergraduate performance in psychiatry at Ibadan, Nigeria. Medical Education 37(12):1091-1093.

Osakuade, JO. (2011). Effectiveness of University Matriculation Examination and Post-UME on the Academic Performance of Nigerian Undergraduate Students. Journal of Education and Practice 2:59-65.

Oyebola, DDO. (2006). The Importance of O Level Grades in Medical School Admission: The University of Ado-Ekiti Experience. African Journal of Biomedical Research 9:15-21.

Salim, BA. (2006). A case study for common and unified entrance examination into Nigerian Universities. Proceedings of Leadership Conference, Nigerian Association of Petroleum Exploration-University Assitance Programme Calabar.

van Ooijen-van der Linden, L., van der Smagt, MJ/, Woertman, L and te Pas. SF. (2017).
Signal detection theory as a tool for successful student selection. Assessment and Evaluation in Higher Education 42:1193-1207.

Yates J, James D (2006). Predicting the "strugglers": a case-control study of students at Nottingham University Medical School. British Medical Journal, BMJ. 332:10091013.

Yates, J and James, D. (2010). The value of the UK Clinical Aptitude Test in predicting preclinical performance: a prospective cohort study at Nottingham Medical School. $B M C$ Medical Education 10(1):1-9 